\title{
The Key and the Countermeasures Research of Shale Gas Fracturing Technology
}

\author{
Yong Tang ${ }^{1, *}$, Bin Wang ${ }^{1}$, Fanhua Zeng ${ }^{2}$ and Jun Wang ${ }^{3}$ \\ ${ }^{I}$ The State Key Laboratory of Oil and Gas Reservoir Geology \& Exploitation, Southwest Petroleum University, \\ Chengdu, Sichuan 610500, China; ${ }^{2}$ Faculty of Engineering and Applied Science, University of Regina, SK, S4S 0A2, \\ Canada; ${ }^{3}$ School of Oil \& Natural Gas Engineering, Southwest Petroleum University, Chengdu, Sichuan 610500, China
}

\begin{abstract}
Shale gas resources are abundantly distributed with low porosity and permeability. Horizontal well and fracturing are prior considerations. Fracturing is a widely-used technology to enhance gas production. In this paper, the author (a) investigated the present stimulation of Barnett and Haynesvile gas fields (Fig. 1) in America, Sichuan basin (Fig. 2) in China and Cooper basin (Fig. 3) in Australia; (b) compared different characteristics and limitations of multi-stage fracturing, water-fracturing, simultaneous fracturing, net fracturing, refracturing and hydraulic jet fracturing; (c) analyzed the critical point of the shale fracturing; (d) offered solutions to the fracturing fluid manufacture, selection and improvement of the fracturing fluids, fractures extension, equipments, fracturing effect evaluation and reservoir protection. It has a farreaching significance to improve fracturing and stimulation of shale gas reservoirs, in view of the high risk, low success ratio and poor stimulation effect the shale gas exploration would face.
\end{abstract}

Keywords: Countermeasures, fracturing technology, fracturing fluid, shale gas.

\section{INTRODUCTION}

In China, shale gas resources are widely distributed in marine and terrestrial sedimentary basin, developed in various geologic epoches. Abundant amount of shale gas resources in China has huge resource potential and exploration prospects. The exploration and development of shale gas in the USA and Canada has reached at a stage of large-scale, especially the exploitation in the Unite State has the international advanced level. According to the U.S. shale gas exploration practices, the development of reservoir fracturing technology exerts an important role in increasing production and promoting business development. This approach has transformed the industry, making it possible to economically stimulate reservoirs that were previously deemed uneconomic. Hydraulic fracturing was firstly applied in the petroleum industry in the 1940s to stimulate productivity in low permeability oil-bearing formations [1]. Since then, hydraulic fracturing has been widely used as a common practice to enhance the recovery of hydrocarbons in low permeability reservoirs, and to deploy sand-prevention in high permeability reservoirs [2].

Fracturing a horizontal well can be considered when one of the following situations is apparent: (a) restricted vertical flow caused by low vertical permeability or lamination, (b) low formation productivity because of low formation permeability, and (c) low stress contrast between the pay zone and the surrounding layers [3-5]. It is used to create extensile

*Address correspondence to this author at the The State Key Laboratory of Oil and Gas Reservoir Geology \& Exploitation, Southwest Petroleum University, Chengdu, Sichuan 610500, China; Tel: +86-13084410503;

Fax: +86-028-83032901; E-mail: tangy@ @wpu.edu.cn artificial fractures around wellbores, for which cement integrity and effective zonal isolation are crucial in long term production, especially in high-pressure and high-temperature reservoirs [6].

\section{THE DIFFICULTY OF SHALE GAS EXPLOITA- TION}

Shale gas is a kind of unconventional natural gas, which accumulates in dark argillutite and high carbon shale through adsorption and extrication (Fig. 4). With the structure of large gas-bearing area, hidden traps, uncertain cap rock and the shorter of hydrocarbon migration distance, shale gas reservoirs are characterized by low porosity and permeability, which are self-generated, self-contained and self-cap gas reservoirs. The required reservoir porosity and permeability are caused by a wide range of regional fractures and abnormal pressures on the stress concentration surfaces, lithologic contact surfaces and lithologic crispbread surfaces [7]. Although the standard of industrial exploitation is not met, the shale gas reservoir has larger surface area to volume ratio, with more than 25 times shale gas adsorption than sandstone reservoirs, the shale gas has a certain exploitation value [8$10]$.

Shale gas lies in the reservoir fractures or be adsorbed on the active surface of shale organics. Gas flow resistance is larger than conventional natural gas. Except that a few fractured gas reservoir having a higher deliverability, shale gas reservoirs generally require the use of artificial fracturing technology. No gas flow was observed for the $40 \%$ of early borehole test in U.S., and 55\% of the absolute open flow was without the industrial value; eventually fracturing horizontal well productivity can exceed $10 \times 10^{4} \mathrm{~m}^{3} / \mathrm{d}$. Critical and 


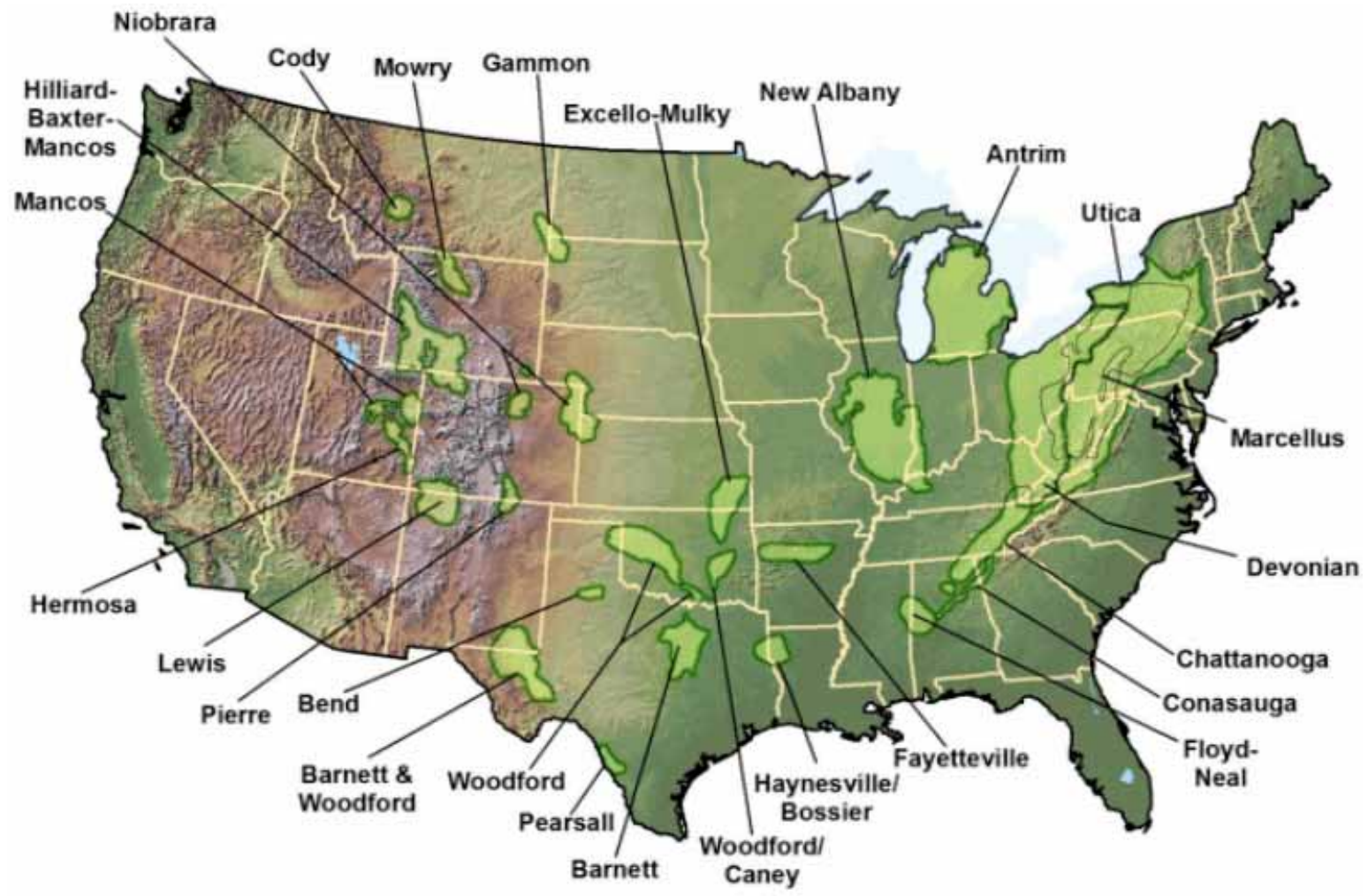

Fig. (1). The USA shale gas reservoirs.

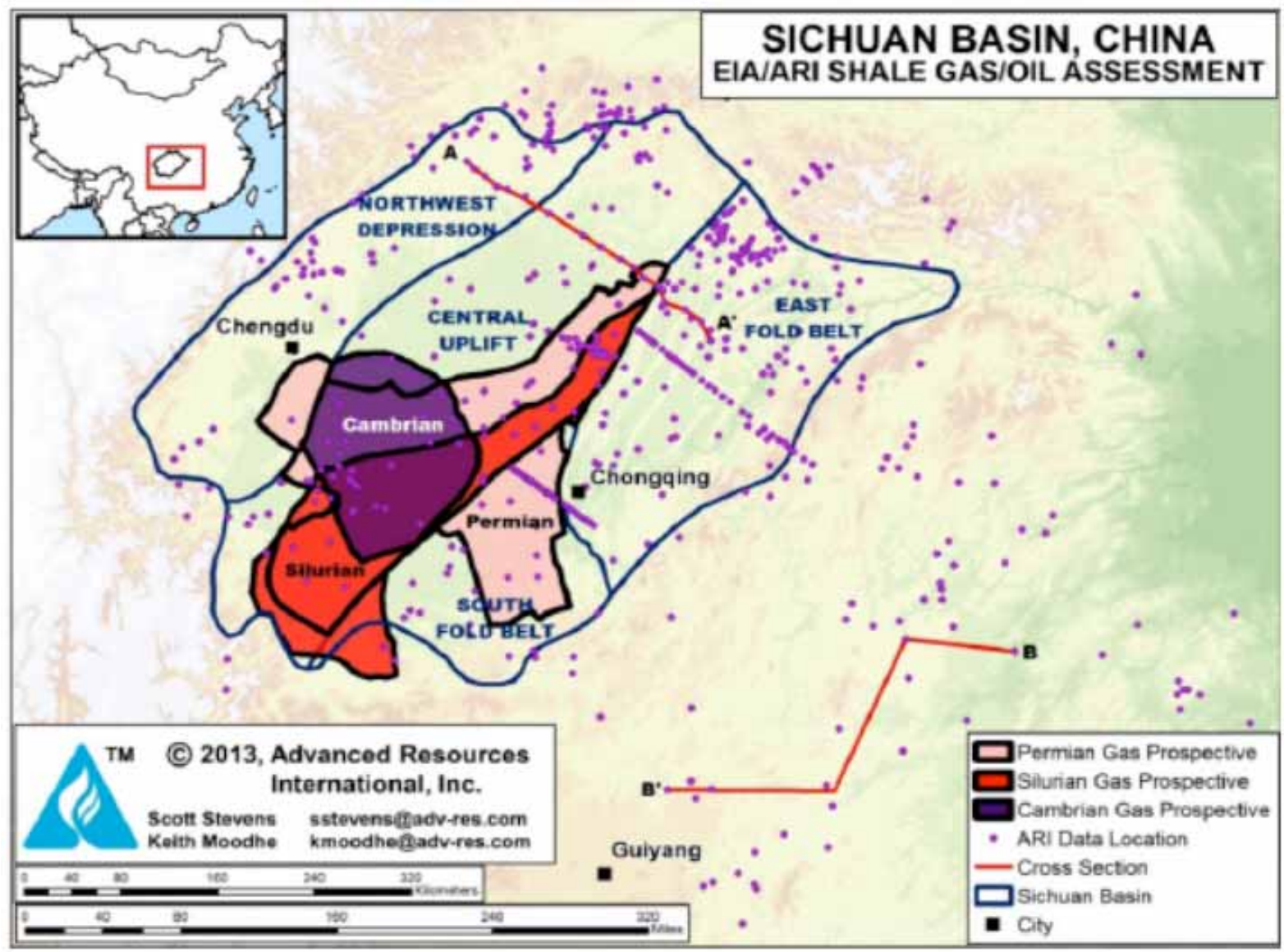

Fig. (2). The map of Sichuan Basin, China. 


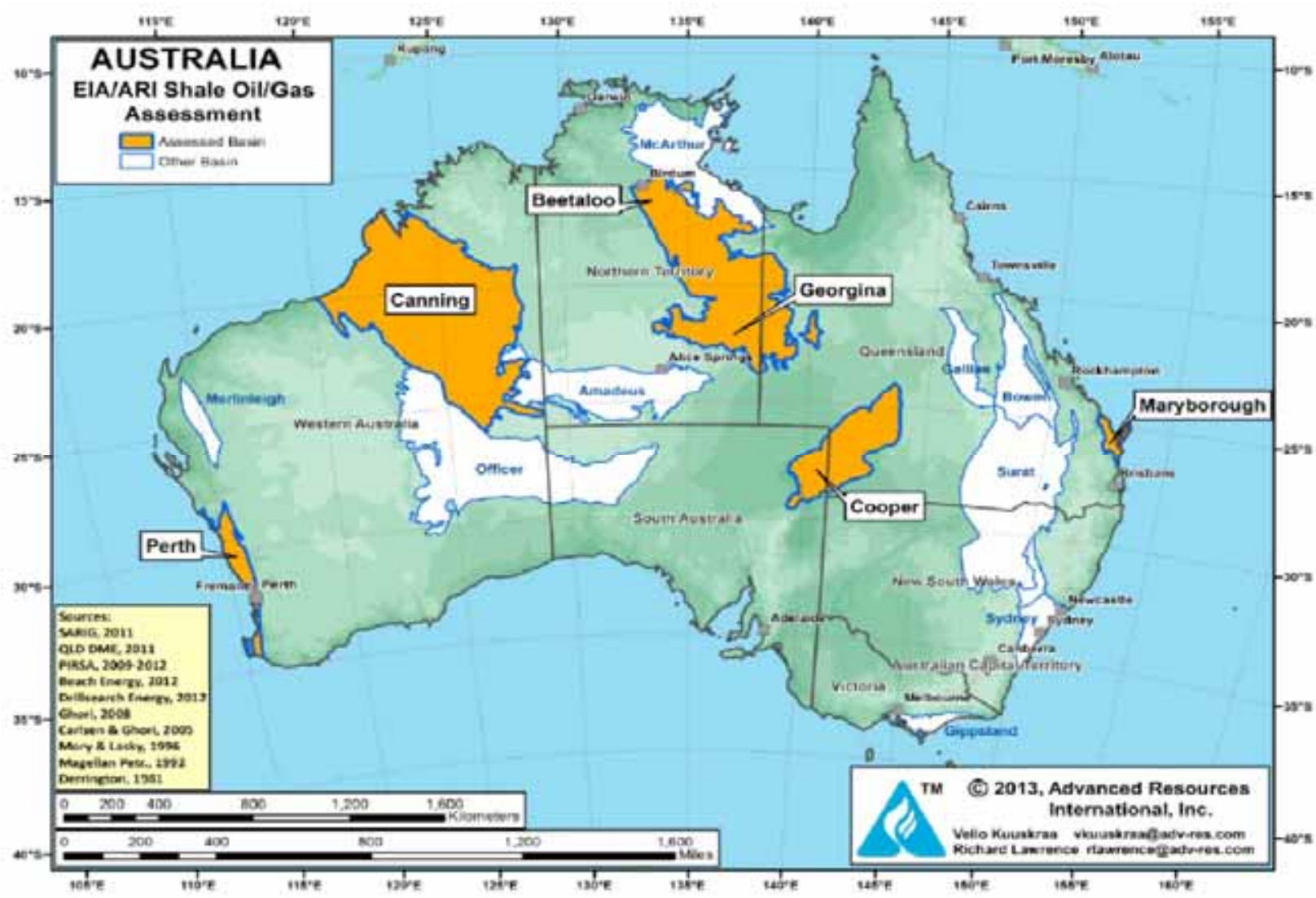

Fig. (3). Australia's assessed prospective shale gas basins.
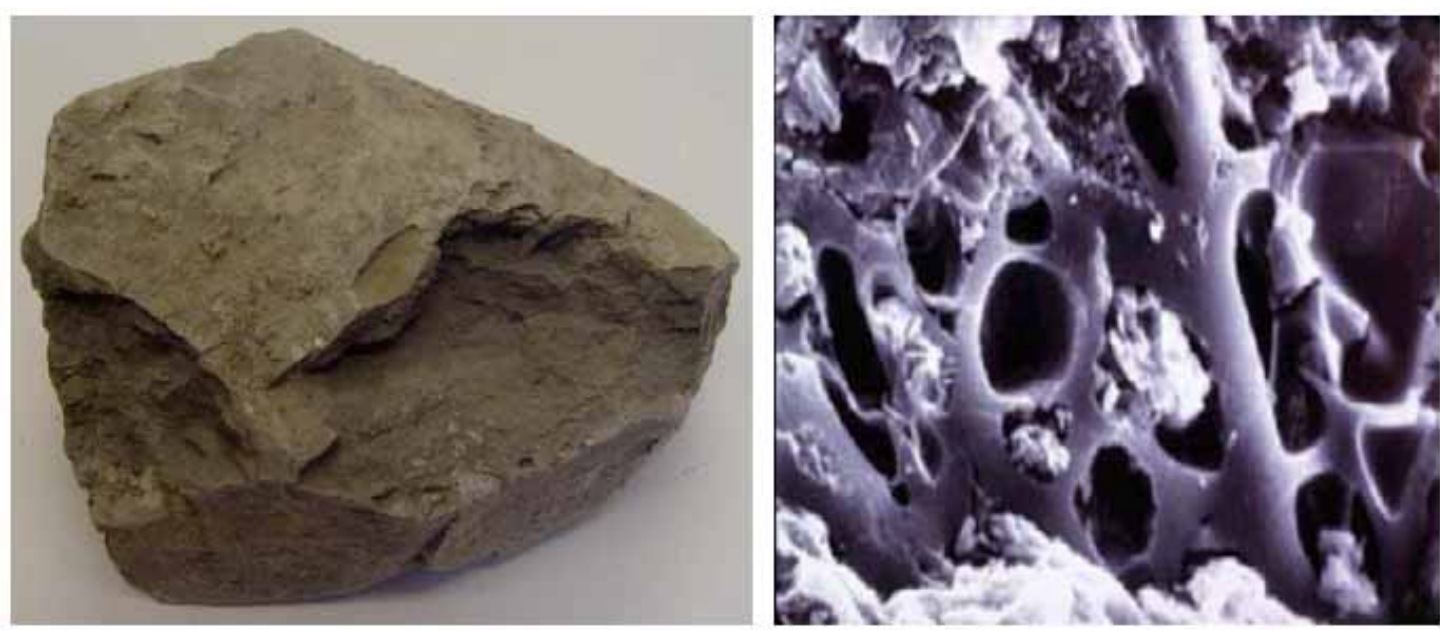

Fig. (4). Shale rock and shale gas pores (Steve Drake, 2007).

intense work on numerous wells has been performed using available data from geology, loggings, cores, pressure transient, et al, to understand and quantify reservoir characteristics, fracturing properties, and flow capacity of wells to come up with plans to improve productivity [11].

Fracturing intends to connect primary fractures. Artificial hydraulic factures can improve the flow permeability, and open the existing natural fractures to form more complex fracture networks. Fracturing technology can not only achieve a higher initial gas production $[12,13]$, but also ex- tend the period of relatively stable production. Differences in lithology, minerals and brittleness determine different fracturing methods.

\section{FRACTURING TECHNICAL ANALYSIS}

Fracturing technology requires connecting cracks as much as possible in the construction process. In this way, very low permeable matrixes can release shale gas under the diffusion effect through the fractures to improve the permeable ability, and ultimately the entire layers form a large, 
complex fracture network system. Abundant natural fractures and minor differences between the horizontal stresses in shale reservoirs are of great importance to the formation of complex fracture network. When fluids flow from fractures into formation, extensional fractures are formed after the injected pressure exceeds the tensile strength. A complex fracture network can be extended by natural fracture which is filled with brittle rock. When the effective stress exceeds the shear strength, natural fractures filled with brittle rock would continue to extend and form a complex fracture network which is different from conventional double wing plane fractures. Among many reasons that may impair well productivity are: (a) fracture not covering the entire pay section, (b) insufficient fracturing half-length, (c) proppant pack permeability, and (d) poor post-fracture cleanup [14].

\subsection{Water Fracturing}

Some additives in water such as water recovery agent (WRA), clay inhibitors, surfactants are used in water fracturing, a method for formation fracturing operation, which relies on hydraulic power to induce more fractures with strong flow conductivity to obtain commercial production in low permeability and large net pay reservoirs. In order to reduce the formation damage and cost, gelled fracture fluid has been adopted instead of the gel fracturing fluid to increase the carrying capacity of sand. WRA is used to reduce friction factor, and surfactants are used to reduce the surface tension of the fluid and improve the rate of fluid recovery.

Water fracturing has advantage in forming long fracture with certain flow ability, eliminating gel damages, accelerating fluid flow-back, extending existing natural fracture to develop interconnecting fracture network, and reducing the cost and suiting reservoirs burial depth from 1.5 to $3 \mathrm{~km}$. However, it has also its drawbacks in low fracture conductivity, such as limited proppant-carrying capacity, quick settlement, limited transport distance of proppant and short effective fractures. Moreover, sand bridge can be formed easily as a result of proppant settling.

\subsection{Simultaneous Fracturing}

Simultaneous fracturing refers to fracturing in two or more adjacent wells at the same time through the facture fluid immigration between wells at high pressure to increase the density and surface area of network. The goal is to expose the shale to more pressures and produce a more complex "three-dimensional web" of fractures by increasing the density of the hydraulic fracture network and increasing the surface area. The drainage area of each wells is enhanced while the fracture fluid is pushed into the space between the two wells. Fig. (5) shows the simultaneous fracturing with three horizontal wells. Inter-well connectivity is used to improve the strength of the work area and maximize connected fracture to increase the short-term production [15]. The technology was firstly used in the Barnett gas field, with a series of pressure tests performed. And it were found that the technique was suitable for the middle and late exploitation.

Change of geo-stress around the fracture wall causes stimulation effect, which minimizes the migration distance of fracturing fluid and proppant between wells. In this case, the technology has great prospects while applied in shale gas exploitation, especially for the dense distribution.

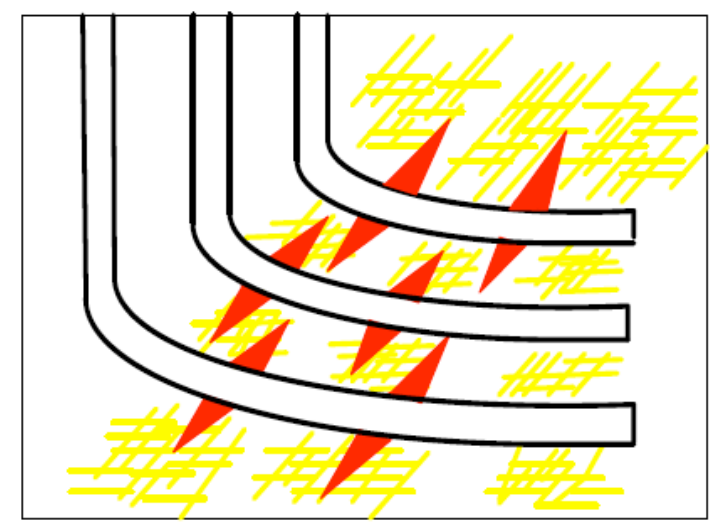

Fig. (5). Simultaneous fracturing with three horizontal wells.

\subsection{Refracturing}

Refracturing is used to enhance production in a poorly fractured well [16]. The stimulation mechanism of refracturing lies in re-orientating fractures, avoiding decrease in permeability caused by proppant failures, re-orientating stress, opening the primary fracture, extending the primary fracture net, rinsing the fracture surfaces, refilling proppant, generating new fractures and obtaining a new effective fracture system. Refracturing is not only suitable for high-yield wells reconstruction and low-yield wells recovery capacity, but also for hypotonic, fracturing bearing, banding heterogeneous stratum.

Refracturing can rebuild the liner flow between the reservoirs and wells, induce the new cracks path to increase the amount and space of fractures, and improve the productivity. According to statistics, the recovery of well through refracturing can increase by $9 \%$; the recoverable reserves can increase about $50 \%$. It is the true that once a well is hydraulically fractured and produces for a period, the stress orientation can change accordingly. And that is the reason of fracturing-deployment. The refracturing orients a different direction up to isotropic point and does not necessarily overlay the initial fracture. Additionally, the fracture is exposed to a new reservoir area. Fig. (6) shows the re-orientation of insitu horizontal stress regime. During the production process, the maximum horizontal stress decreases faster than the minimum horizontal stress due to the higher depletion in the fracture direction. As a result, the second fracture may propagate orthogonally to the first one up to the isotropic point. According to the Barnett field data, the productivity of refracturing is 2.5 to 5 times larger than the first fracturing. It shows that stimulation effects are fairly obvious. However, the poor initial fracturing mainly occurs from the premature screen-out; severe proppant degradation and damage.

Currently, the horizontal well refracturing technology is still in development, including shunt refracturing and cement-based or uncemented refracturing.

\subsection{Multi-stage Fracturing}

Multi-stage fracturing is aimed to form multi-section fractures which are perpendicular to well trajectory to in- 
crease the contact surface between wellbore and reservoirs and improve the formation permeability. Multi-stage fracturing technology is the main hydraulic fracturing technology for shale gas application [17]. The horizontal well technology has been widely used in shale gas production in America. It showed that the daily output per well can increase significantly, and the production cycle of gas well can be extended extraordinarily. Even though horizontal wells generally cost 2 more times than vertical wells in drilling, they produce more than twice as vertical wells do. Limited to technical issues, the horizontal well fracturing generally uses 1 or 2 sections. However, fracturing sections will gradually increase with the pace of technology progress.

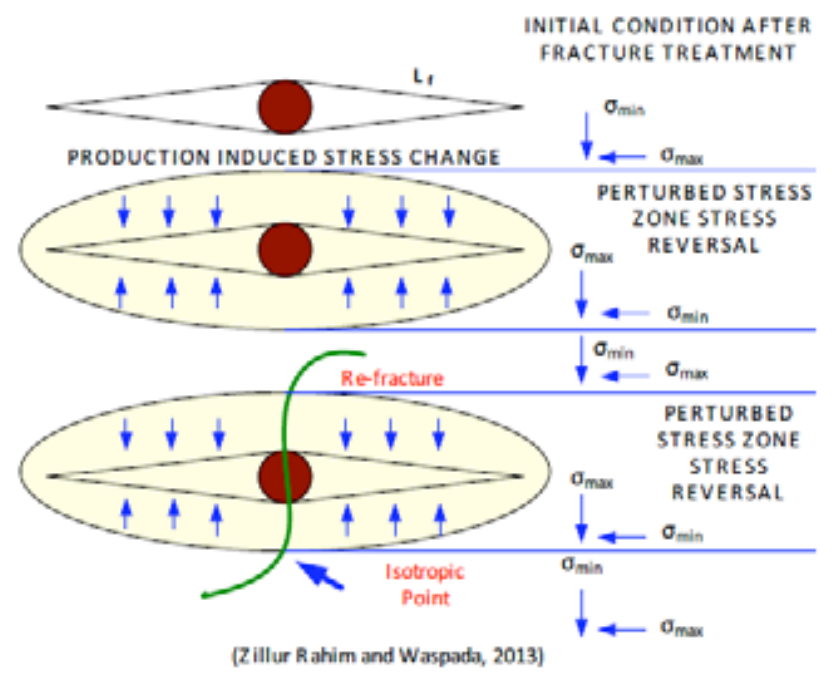

Fig. (6). Re-orientation of in-situ horizontal stress regime.

\subsection{Hydraulic Jet Fracturing}

Hydraulic jet fracturing is a set of technology regarding hydraulic perforation, fracturing, and integration-isolation. It can accurately create man-made fractures and complete the perforations. The technology is restricted by the depth of well and sand-carrying scale rather than the horizontal well completion method. Hydraulic jet fracturing was first used in Barnett gas field in 2005. Among them, about 50\% wells have contributed technical and economic success.

High-speed and high-pressure sand-carrying technology is applied to perforation. The path between the reservoir and bore hole is established to strengthen fluid flow. One or more injection channels are formed in a bore hole with the hydraulic action, instead of packer operation. HJF is not a suitable option for ST under the condition of low bore pressure; rapid-creation of fractures and problem-solving needs for open hole completion.

In addition to the several fracturing technologies mentioned before, large-scale hydraulic fracturing and nitrogen foam fracturing are also effective methods for fracturing operation.

\section{ANALYSIS OF FRACTURING FLUIDS TECH- NOLOGY}

Shale reservoirs contain clay minerals and are watersensitive. In other words, the clay minerals in reservoir will swell up after the water injection. And then they will obstruct the pores, cause the decrease of production and collapse of borehole wall. Furthermore, the selection of reasonable fracturing fluids and appropriate additives is a vital factor to shale gas exploitation. Fracturing fluid could exert a critical influence on success of a stimulation treatment. A cost-efficient solution could be obtained with effective fracturing fluids. And it means that the fracturing fluids can be compatible with formation (clay mineralogy), can increase fracturing efficiency by conveying enough proppant to establish sufficient fracture conductivity, and avoid damage to the formation [18].

According to the geographical and water conditions, continuous-mixed fluid and transition fracturing tank are usually used to make up fracturing on the ground in the United States. Friction-reducing additive and guar are dissolved and then they swell up three minutes. And the amount of continuous mixing is $15.9 \mathrm{~m}^{3} / \mathrm{min}$. Four compartments sand cars are applied for sand storage in the United States, which can meet the requirement of different size proppant storage and the maximum speed of transmission $\left(5.1 \mathrm{~m}^{3} / \mathrm{min}\right)$.

\subsection{Fracturing Fluids}

Fracture fluids aim to create sufficient width for proppant entrance; provide a desired net pressure to either treat some desired height growth or prevent breaking into some undesirable zones; and afford carrying capability to transport proppant and control the fluid loss. The favorable fluids have an easily-measured controllable viscosity, controllable fluid loss characteristics. And that means they would not damage the fracture or interact with the formation fluid [19].

Friction-reduction fracturing fluid, fibrous fracturing fluid and river fracturing fluid are the most widely used fluids. Shale contains a variety of acid-soluble minerals which evenly distribute in the shale matrix, bedding and primary cracks. These minerals are dissolved and removed when they are in contact with reaction fluids, which increases the surface of fractures, improves the desorption rate of shale gas and enhances the diffusion in the fracture network.

In order to meet the need of creating shear fractures and volume of open fractures, fracturing fluids volume size should be moderate. Layered shale will produce the tensile fractures and shear fractures, opening the natural micro fracture. Besides, some haydites are used to reduce crack filtration and near well bore friction, prevent premature screenout.

Generally, waterfrac is ideal for creating a fracture network (i.e., increasing fracture length/volume while minimizing formation damage). A crosslinked or linear gel fluid is the appropriate choice for increasing fracture conductivity.

\subsection{Additives}

The additives play an important role in spite of the minor contribution to the total mass of liquid (less than 1\%). Common additives can be classified into 13 kinds. Acid is capable of promoting minerals dissolution and generating fracture. Anti-corrosion is able to remove the corrosion products generated from bacteria. Demulsifier is function of delay the rupture time of gel. Meanwhile, buffer is used in conjunction with polymer for attaining the optimal $\mathrm{pH}$ of polymer hydra- 
tion. Crosslinker agent functions as the viscosity-maintainer of fracturing fluid under the condition of high temperature and low friction. Gel is characterized by improving the concentration of water to carry sand and inhibit chemical degradation. Fe stabilizer is used to avoid MOX precipitation. Anti-sloughing agent can prevent the reaction between the fluids and clays. PH conditioner can keep the effect of some components. Antifoulant can prevent fouling in the pipeline. SAA can reduce the surface tension of the fracture fluid and increase the rate of return. Proppant can prevent the fracture closure. Furthermore, the selection of proppant can affect initial productivity, conductivity, and production reliability.

\section{CHINA SHALE GAS FRACTURING POLICY}

In China, the shale gas resources estimation is speculative and sketchy (China Unconventional Gas Resources are shown in Fig. 7), the estimated potential resources in China amount to 1084 to 3530 Tcf $[20,21]$, For geographical distribution, target areas can be divided into four regions, as shown in Fig. (8), China shale gas reservoirs are different from the U.S. in many aspects. For example, the burial depth of Sichuan basin is deeper than the majority gas reservoirs of the U.S., the depth of the U.S. shale gas reservoirs is 800 $2600 \mathrm{~m}$, while the depth of the shale gas reservoirs in $\mathrm{Si}$ chuan Basin is 1500 3500m. The deep burial depth not only increase the difficulty of exploitation, but also incur many problems on the project. The following problems occur in China: Firstly, old formation outcrops, poor drilling, slow mechanical drilling speed, short bit footage. Secondly, the water breakthrough at the upper strata, well exposure at the lower strata, gas drilling restriction. Thirdly, down hole complex result from well bore instability, pores and fractures growth in the longitudinal section. Lastly, late start of extending horizontal well cementing and stimulation technolo- gies in China. For all reasons above, it is not wise to mechanically copy from America shale gas exploitation experience. China should conduct the corresponding researches which combine with the specific reservoir conditions [22].

\subsection{Innovation is the Driving Force}

Combined with China's reservoir characteristics and geological conditions, theoretical study needs to be promoted to develop a series of suitable technologies and tools for China fracturing application. The shale gas in the shale matrix can only be released relying on diffusion through the surface of organic, the stress sensitivity of natural fractures is the key factor to influence the gas flow, and the slippage effect is more serious in smaller pores, so the understanding of geological characteristics of shale gas and permeability mechanism should be respected. Efforts will be made on reservoir properties, TAT, Coiled tubing blast annular infinite stagesectional fracture, longer horizontal section $(1200 \mathrm{~m})$ and fracture monitoring technology. And effective grid system, fracturing fluids and large-scale sand-fracturing experiments should be carried out. According to the technological level of China, shale gas exploitation of more than 3000 meters is more difficult. Hence, it is important to research on how to exploit this kind of shale gas.

\section{2. "Integration" and "Factory" is the Key to Reducing the Cost}

Integrated reservoir exploitation refers to the combination of gas reservoirs exploration and stimulation. Equipments and technologies are used to establish the intelligent and integrated system of shale gas. A set of shale gas exploitation is optimized through smoothing the each construction link and taking the design core of every step into consideration.

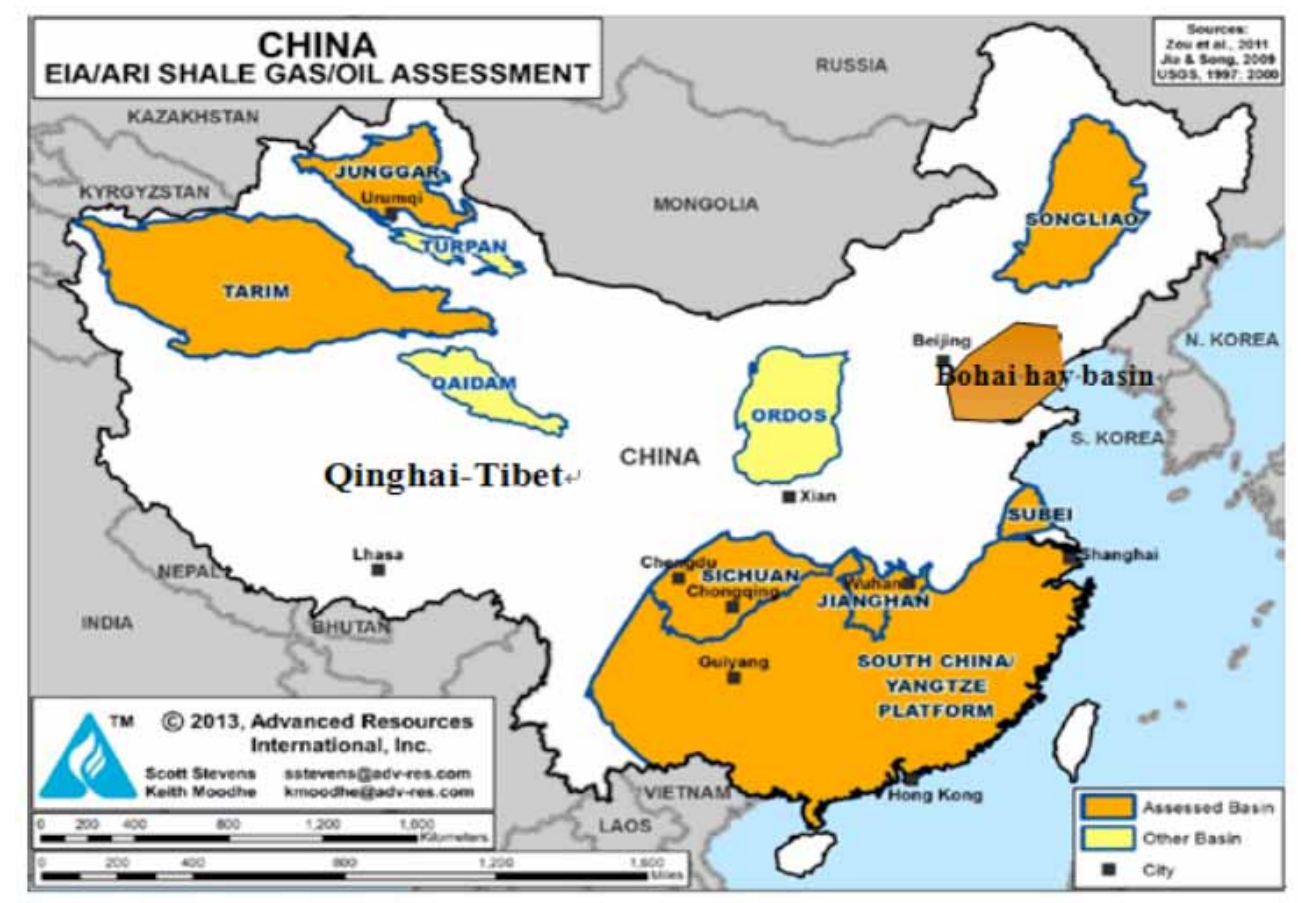

Fig. (7). The Shale Gas Resources in China. 


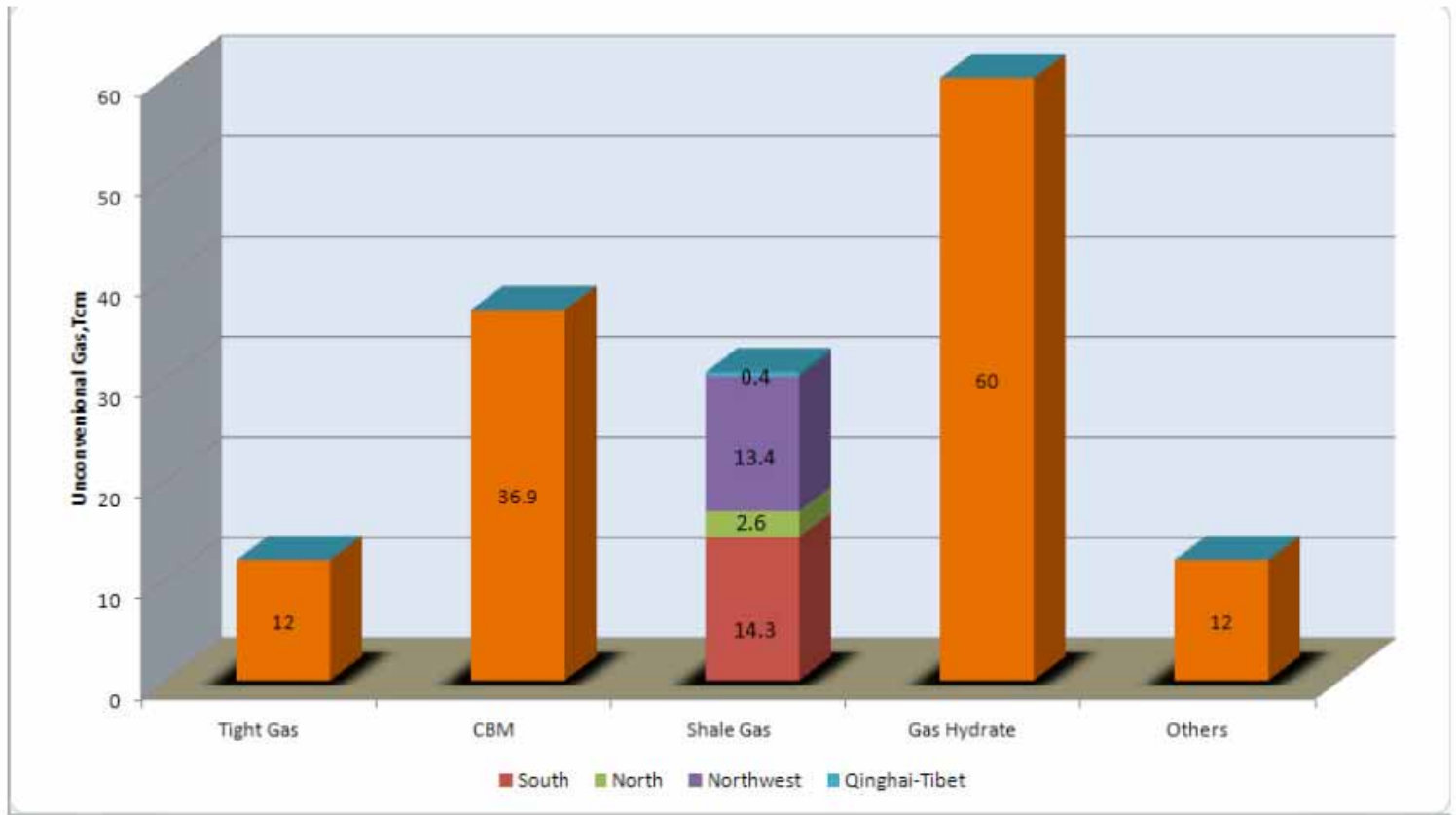

Fig. (8). China Unconventional Gas Resources (After Ma, 2009).

South (Sichuan Basin, Jianghan Basin and Chuxiong Basin), North (Ordos Basin, Bohai Bay Basin, Songliao Basin), Northwest (Tarim Basin and Qaidai basin), and Qinghai-Tibet.

Factory exploitation refers to the favorable choice that reduces the time of cost recovery cycle and accelerates the speed of reservoir exploitation. At present, Sichuan gas field in Weiyuan has costed 100 million on drilling with the deviation of depth and azimuth. More shale gas wells are in favor of controlling the capital risk, speeding the costrecovering and profits, if the advanced technology available. It was showed that the fee of reservoirs stimulation and drilling account for about $80 \%$ of the total fee of a well in the United States. In addition, the fee is mainly dominated by horizontal length, numbers of segments fracturing and the scale of fracture fluid. In this case, factory model is a vital determination.

\subsection{Tool Development is the Core of Fracturing Tech- nology}

Further study is mainly to improve domestic fracturing tools and integrate the related equipment system of fracturing technology [23]. With respect to the reconstruction of horizontal well, further improvement is mainly to enhance the level of well external packer staged fracturing technology, injection of staged fracturing technology, slip packer staged fracturing technology. In order to meet the requirement of the exploitation of shale gas, perfect horizontal well fracturing mode should be established. "Water jet + multilevel Slide" fixed pipe staged fracturing technology and dual hydraulic jet ejector multi-segmented clusters fracturing techniques need to be further developed. It is advised to learn more from the foreign advanced technology and resources ,and to conduct independent research to break the monopoly, eventually achieve the localization of fracturing tools.

At present, a considerable portion of fracturing equipment are imported, such as fracturing trucks, Monitoring vehicles and down hole equipments. It is necessary to investigate on type 2800 and type 3000 fracturing truck to improve the pumping rate and save spaces.

\subsection{Optimization of Fracturing Technology to Reduce Cost}

More fracturing fluids are required to satisfy the extension of the horizontal section. It is necessary to handle with the flow back fluids environmentally to minimize any pollution; research on fracturing fluids recycling technology to reduce the cost; optimize the design of each step in the the process of fracturing to reduce the high cost and extend the service life of high performance fracturing fluids and proppant material; study high-strength low-density fracturing fluid with low friction slippery water; control the water lock; change the wettability reversal capacity; and reduce the concentration. Optimization of well pattern and development of cluster horizontal well technique create condition for simultaneous fracturing.

\section{CONCLUSION}

Fracturing design optimization by taking natural advantage of the open-fracture network is a key for successful development in shale reservoir. Hydraulically-induced tensile force; shear fractures with natural fractures and connected and re-activating natural fractures are some of the keys for gas production in shale.

Even though the shale gas resources are plentiful in China, the shale gas research and exploration are in the early stage. With the rapid development of society, the requirements from natural gas resources are increasingly urgent. In this case, it is necessary to deploy the development of fracturing technology. Shale gas fracturing technology will de- 
termine China's future development of shale gas. Continuous study and understanding will make new and greater contribution to the exploration and development of shale gas.

\section{CONFLICT OF INTEREST}

The authors confirm that this article content has no conflict of interest.

\section{ACKNOWLEDGEMENTS}

This work was financially supported by 973 Program of China under Grant No. 2014CB239205 and National Science Foundation of P. R. China No.51274173.

\section{REFERENCES}

[1] H.Y. Wang, and M. Marongiu-Porcu, "A unified model of matrix permeability in shale gas formations", In: SPE 173196 at the SPE Reservoir Simulation Symposium, Houston, Texas, USA, 23-25 February, 2015.

[2] C.A. Ehlig-Economides, M. Taha, H.D. Marin, E. Novoa, and O. Sanchez, "Drilling and completion strategies in naturally fractured reservoirs", In: SPE 59057 presented at the 2000 SPE International Petroleum Conference and Exhibition in Mexico held in Villahermosa, Mexico, 1-3 February, 2000.

[3] W. Yu, Z. Luo, F. Javadpour, A. Varavei, and K. Sepehronoori, "Sensitivity analysis of hydraulic fracture geometry in shale gas reservoirs", Journal of Petroleum Science and Engineering, vol. 113, pp. 1-7, 2014.

[4] Y. Jun, and H.S. Zeng, "Pooling conditions and exploration prospect of shale gas in Xujia Formation in the Western Sichuan Depression", Natural Gas Industry, vol. 28, pp. 18-25, 2008.

[5] K.C. Wilson, and L.J. Durlofsky, "Optimization of shale gas field development using direct search techniques and reduced-physics models", Journal of Petroleum Science and Engineering, vol. 108, pp. 304-315, 2013.

[6] A. Shadravan, and M. Amani, "HPHT101- what every engineer or geoscientist should know about high temperature wells", In: SPE 163376 at the SPE Kuwait International Petroleum Conference and Exhibition, Kuwait, 10-12 December, 2012.

[7] D.M. Jarvie, R.J. Hill, T.E. Ruble, and R.M. Pollsatro, "Unconventional shale-gas systems: The Mississippian Barnett Shale of northcentral Texas as one model for thermogenic shale-gas assessment", AAPG Bulletin, vol. 91, pp. 475-499, 2007.

[8] W. George, D. Barry, D. Robert, K. Kerrihard, L. Austbo, and B. McPherson, "Simultaneous hydraulic fracturing of adjacent horizontal wells in Woodford Shale", In: SPE 119635 at SPE Hydraulic Fracturing Technology Conference in The Woodlands, Texas, USA, 19-21 January, 2009.

[9] W.L. Ding, C. Li, C.Y. Li, C.C. Xu, K. Jun, W. Zeng, and L.M. $\mathrm{Wu}$, "Fracture development in shale and its relationship to gas accumulation", Geoscience Frontiers, vol. 3, pp. 97-105, 2012.
[10] S.Y. Wang, X.L. Luo, and R.S. Hurt, "What we learned from a study of refracturing in Barnett Shale: an investigation of completion/fracturing, and production of re-fractured wells", In: IPTC 17081 at International Petroleum Technology Conference, Beijing, China, 26-28 March, 2013.

[11] Z. Rahim, D. Waspada, H. Al-Anazi, and A. Al-Kanaan, "Effective analytical approach to enhance productivity of low producing gas wells", In: SPE 164614 Presented at North Africa Technical Conference and Exhibition, Cairo, Egypt, 15-17 April, 2013.

[12] H.Q. Song, Q.P. Liu, D.W. Yang, M.X Yu, Y. Lou, and W.Y Zhu, "Productivity equation of fractured horizontal well in a waterbearing tight gas reservoir with low-velocity non-Darcy flow", Journal of Natural Gas Science and Engineering, vol. 18, pp. 467473, 2014.

[13] M.Y. Soliman, J. Daal, and L. East, "Fracturing unconventional formations to enhance productivity", Journal of Natural Gas Science and Engineering, vol. 8, pp. 52-67, 2014.

[14] H. Sone, and M.D. Zoback, "Time-dependent deformation of shale gas reservoir rocks and its long-term effect on the in situ state of stress", International Journal of Rock Mechanics and Mining Sciences, vol. 69, pp. 120-132, 2014.

[15] C.M. Freeman, G. Moridis, D. 1lk, and T.A. Blasingame, "A numerical study of performance for tight gas and shale gas reservoir systems", Journal of Petroleum Science and Engineering, vol. 108, pp. 22-39, 2013.

[16] L.D. Mi, H.Q. Jiang, and J.J. Li, "The impact of diffusion type on multiscale discrete fracture model numerical simulation for shale gas", Journal of Natural Gas Science and Engineering, vol. 20, pp. 4-81, 2014.

[17] S. French, J. Rodgerson, and C. Feik, "Re-fracturing horizontal shale gas wells: case history of a Woodford Shale pilot project", In: SPE 168607 Presented at SPE Hydraulic Fracturing Technology Conference, Texas, USA, 4-6 February, 2014.

[18] W.T. Stringfellow, J.K. Domen, M.K. Camarillo, W.L. Sandelin, and S. Borglin, "Physical, chemical, and biological characteristics of compounds used in hydraulic fracturing", Journal of Hazardous Materials, vol. 275, pp. 37-54,2014.

[19] S.C. Deng, H.B. Li, G.W. Ma, H. Huang, and X. Li, "Simulation of shale-proppant interaction in hydraulic fracturing by the discrete element method", International Journal of Rock Mechanics and Mining Sciences, vol. 70, pp. 219-228, 2014.

[20] M. Melikoglu, "Shale gas: Analysis of its role in the global energy market", Renewable and Sustainable Energy Reviews, vol. 37, pp. 460-468, 2014.

[21] H.C. Lau, and M. Yu, "Production technology challenges of tight and shale gas production in China", In: IPTC 17906 presented at International Petroleum Technology Conference, Beijing, China, 26-28 March, 2013.

[22] Z. Dawei, "Main solution ways to speed up shale gas exploration and development in China", Natural Gas Industry, vol. 31, pp. 1-5, 2011.

[23] S.H. Stevens, K.D. Moodhe, and V.A. Kuuskraa, "China shale gas and shale oil resource evaluation and technical challenges", In: SPE 165832 Presented at SPE Asia Pacific Oil and Gas Conference and Exhibition, Jakarta, Indonesia, 22-24 October, 2013.

(C) Tang et al.; Licensee Bentham Open.

This is an open access article licensed under the terms of the Creative Commons Attribution Non-Commercial License (http://creativecommons.org/licenses/by-nc/3.0/) which permits unrestricted, non-commercial use, distribution and reproduction in any medium, provided the work is properly cited. 